\title{
Acute satiety response of mammalian, avian and fish proteins in dogs
}

\author{
Brittany M. Vester Boler ${ }^{1}$, Trevor A. Faber ${ }^{1}$, Laura L. Bauer ${ }^{1}$, Kelly S. Swanson ${ }^{1}$, Scott Smiley ${ }^{2}$, \\ Peter J. Bechtel ${ }^{2,3}$ and George C. Fahey $\mathrm{Jr}^{1 *}$ \\ ${ }^{1}$ Department of Animal Sciences, University of Illinois, Urbana, IL 61801, USA \\ ${ }^{2}$ University of Alaska, Fairbanks, Kodiak, AK 99615, USA \\ ${ }^{3}$ USDA/ARS, Kodiak, AK 99615, USA
}

(Received 15 October 2010 - Revised 9 February 2011 - Accepted 14 March 2011 - First published online 27 June 2011)

\section{Abstract}

Fish proteins have been reported to be more satiating than meat proteins. The objective was to determine the effect of different animal protein pre-meals on satiety. A total of ten intact female hounds were fed pork loin, beef loin, chicken breast, salmon fillet or pollock fillet. Each pre-meal was fed to contain $100 \mathrm{~g}$ protein. Blood was collected at 0, 5, 15, 30, 60, 90 and 120 min postprandially and analysed for glucose, insulin, total ghrelin, active glucagon-like peptide-1 (GLP-1) and plasma amino acids (AA). Dogs were fed $2 \times$ metabolisable energy, $3 \mathrm{~h}$ following the pre-meal, and intake was determined 30, 60, 180 and $1440 \mathrm{~min}$ after food presentation. Glucose decreased over time $(P<0 \cdot 001)$, but was lowest $(P=0.01)$ when dogs consumed pollock or chicken. Insulin increased $(P<0 \cdot 0001)$ over time, and was greater $(P=0 \cdot 09)$ when dogs consumed salmon. GLP-1 increased $(P<0 \cdot 001)$ over time, and was greatest $(P=0 \cdot 04)$ when dogs consumed beef. Ghrelin decreased $(P<0 \cdot 0001)$ over time for all pre-meals. The tryptophan:large neutral AA ratio tended to be greater $(P=0 \cdot 08)$ when dogs consumed pork, salmon and pollock. Different protein sources may influence blood markers in dogs, but it does not appear that fish substrates have different satiating abilities than mammalian or avian sources.

Key words: Dogs: Glucagon-like peptide-1: Ghrelin: Protein: Satiety

Obesity is a growing problem in both companion animal and human populations in many countries around the world. Diets with differing macronutrient compositions that increase satiety have been evaluated in the past, but data evaluating specific sources of macronutrients are more limited. It has been well documented that satiety can be affected by the macronutrient composition of the diet ${ }^{(1)}$. Proteins, specifically, are noted to be the most satiating; however, dietary source may influence satiety. Satiety is regulated by the central nervous system, including long-term energy utilisation and body stores (multiple meal intake), and short-term energy intake and utilisation (meal intake) $^{(2)}$, allowing multiple systems to be targeted when trying to influence satiety. Orexigenic modifiers increase food intake and decrease energy expenditure (for example, ghrelin), while anorexigenic modifiers decrease food intake and increase energy expenditure (for example, glucagon-like peptide-1 (GLP-1), insulin) ${ }^{(3)}$. Finding protein sources that can more effectively decrease orexigenic compounds and increase anorexigenic compounds may help decrease food intake.

Of the satiety-related hormones, some commonly analysed include an orexigenic compound, ghrelin, and GLP-1. Ghrelin, produced by gastric X/A-like cells, increases during fasting, leading to increased food intake. High-protein diets, when compared with high-carbohydrate diets, have been reported to decrease postprandial ghrelin concentrations, but with a more moderate and prolonged effect on ghrelin suppression $^{(4)}$. GLP-1 is thought to regulate food intake by playing a role in the ileal brake phenomenon ${ }^{(5)}$ and through a direct effect on the hypothalamus ${ }^{(6,7)}$, leading to a reduced food intake or cessation of a meal, thereby decreasing the rate of nutrient influx into the blood ${ }^{(8)}$. Circulating GLP-1 concentrations are influenced by macronutrient concentration; therefore, it is possible that fish substrates may lead to increased circulating GLP-1 and to a reduction in food intake.

Circulating plasma amino acids (AA) also have been implicated in the satiety response to a meal, including insulinogenic AA. The theory of AA influencing food intake was described by Mellinkoff ${ }^{(9)}$, and suggests that the AA profile of food and the modifications this profile undergoes based on the needs of the intestine and liver may regulate its role in satiety. It also has been suggested that the tryptophan:large neutral AA (LNAA) ratio after a meal can lead to changes in food intake; specifically, a reduction in this ratio may increase food intake.

Abbreviations: AA, amino acid; AUC, area under the curve; GLP-1, glucagon-like peptide-1; LNAA, large neutral amino acids; ME, metabolisable energy. 
High-protein meals fed to human subjects have been shown to prolong satiation as compared with high-carbohydrate meals ${ }^{(10,11)}$, but less research exists on the effect of the dietary source of protein on satiety. Holt et al. ${ }^{(1)}$ developed a satiety index of common foods in humans and noted that fish was the most satiating protein source (compared with beef steak, baked beans, eggs, cheese, lentils and a white bread standard). A reduction in food intake following a fish pre-load or meal compared with beef and/or chicken has been noted in human subjects ${ }^{(12,13)}$. These authors proposed that this prolonged satiety may be related to the fact that fish protein AA took longer to reach peak plasma concentrations compared with a beef or chicken meal, as well as increased plasma taurine and methionine concentrations ${ }^{(12)}$. While these effects have been noted, the mechanism of this satiety effect is unknown.

Dogs are an appropriate model to assess satiety response of humans due to similarities regarding select feeding behaviours. Dogs, like humans, will continue to consume a highly palatable diet beyond their energy requirements. Therefore, the food intake response following a pre-meal may simulate a response by healthy adult humans. Also, it was our decision to use the dog as a model for humans due to the nature of our substrates (dried, ground meat), which would not be palatable to human subjects. Finally by using the dog as a model for humans, we were able to better control other factors that influence hormone response and voluntary food intake, including taste preference, body weight and exercise pattern. Finally, these data provide information about canine diets, as influencing satiety in dogs to control body weight is also of importance.

The objective of the present study was to determine the effect of beef, chicken, pork or fish protein pre-meals on postprandial satiety response, plasma AA concentrations and $24 \mathrm{~h}$ food intake in healthy, adult dogs. We hypothesised that fish protein would be more satiating compared with mammalian and avian sources.

\section{Materials and methods}

\section{Animals, diets and substrates}

A total of ten purpose-bred, intact female hounds (Butler Farms, Clyde, NY, USA) with hound bloodlines were utilised in the present experiment (aged $4.5 \pm 0 \cdot 1$ years; $22.1 \pm 2 \cdot 0 \mathrm{~kg}$ body weight). Dogs were individually housed $(2.3 \mathrm{~m} \times 1 \cdot 1$ $\mathrm{m}$ pens) in a climate-controlled room in the Edward R. Madigan Laboratory on the University of Illinois campus. Pens allowed for nose - nose contact between dogs in adjacent runs and visual contact with all dogs in the room. A $16 \mathrm{~h}$ light $-8 \mathrm{~h}$ dark cycle was used. All dogs were fed the diets to maintain body weight throughout the study, but were allowed $2 \times$ the metabolisable energy (ME) requirement during the protein postprandial tests. ME was determined based on previous feeding of the diet to maintain the body weight of each animal individually. All animal procedures were approved by the University of Illinois Institutional Animal Care and Use Committee (IACUC) before animal experimentation.
Dogs were fed an experimental diet throughout the experiment. The diet contained poultry by-product meal, maize and brewer's rice as the main ingredients and was formulated to contain $30 \%$ crude protein and $20 \%$ fat. Food intake was determined daily. We utilised five substrates in the present study including pork loin, beef loin, chicken breast, salmon fillet and pollock fillet. All sources were previously utilised as the main protein source in diets fed to dogs to determine nutrient digestibility ${ }^{(14)}$. The composition of these substrates also was determined previously by Faber et al. ${ }^{(14)}$. Briefly, all substrates were dried at $71^{\circ} \mathrm{C}$ for $6 \mathrm{~h}$. They were then ground to pass a $2 \mathrm{~mm}$ screen and were stored at $4^{\circ} \mathrm{C}$ until used.

\section{Experimental design}

The present study was conducted as replicated $5 \times 5$ Latin squares in a completely randomised design. Testing was conducted at the same time each day with 2 or $3 \mathrm{~d}$ between tests. Dogs were food-restricted for a minimum of $12 \mathrm{~h}$ before collection days. Dogs were fed an amount of substrate required to provide $100 \mathrm{~g}$ protein in $200 \mathrm{ml}$ water. Water was added to the substrates to ease consumption of the dried meat material. Blood was collected before feeding the substrate (time 0), and at 5, 15, 30, 60, 90 and $120 \mathrm{~min}$ postprandially. Dogs were fed $2 \times$ the ME requirement $3 \mathrm{~h}$ following the feeding of the protein substrate to determine a satiety response. Food was weighed at 30, 60, 180 and $1440 \mathrm{~min}$ after food presentation.

\section{Chemical analyses}

Postprandial blood samples were analysed for plasma glucose, serum insulin, plasma AA, serum total ghrelin and plasma active GLP-1. Blood was collected by jugular venepuncture into $10 \mathrm{ml}$ syringes and immediately transferred to appropriate vacutainer tubes. Blood used to measure plasma AA and glucose was transferred into vacutainer tubes containing lithium heparin to prevent clotting and centrifuged at $2000 \mathrm{~g}$ at $4^{\circ} \mathrm{C}$ for $15 \mathrm{~min}$. Blood $(1 \mathrm{ml})$ was transferred to a vacutainer tube containing an EDTA anti-coagulant and $10 \mu$ dipeptidyl peptidase IV, according to the manufacturer's instructions, and centrifuged at $1000 \mathrm{~g}$ at $4^{\circ} \mathrm{C}$ for $10 \mathrm{~min}$ for measurement of active GLP-1. All other blood was placed in tubes containing no anti-coagulant where it was allowed to clot, and then centrifuged at $1300 \mathrm{~g}$ for $10 \mathrm{~min}$. After centrifugation, the supernatant fraction was removed and was either immediately analysed (glucose) or stored (insulin and plasma $\mathrm{AA},-20^{\circ} \mathrm{C}$; GLP-1 and total ghrelin, $-80^{\circ} \mathrm{C}$ ) until analysed. Plasma glucose was analysed using the glucose peroxidase method (Sigma-Aldrich, St Louis, MO, USA). Serum was analysed for insulin using a Rat Insulin Enzyme Immunoassy kit (Cayman Chemical, Ann Arbor, MI, USA) noted to work in dogs ${ }^{(15)}$ Following a 10-fold dilution, total serum ghrelin was determined using a total ghrelin (rat, mouse) enzyme immunoassay (EIA) kit (Phoenix Pharmaceuticals, Inc., Burlingame, CA, USA) according to Vester et $a l^{(16)}$ and noted to work in dogs ${ }^{(17)}$. Plasma active GLP-1 concentrations were determined 
using the Glucagon-Like Peptide-1 (Active) ELISA kit (Millipore, St Charles, MO, USA) noted to work in dogs ${ }^{(17)}$. Plasma GLP-1 concentrations were determined using a linear-linear spline fit curve. Plasma AA concentrations were determined using ion-exchange analysis with post-column ninhydrin detection using lithium-based eluants after treatment with SERAPREP (Pickering Laboratories, Inc., Mountain View, CA, USA).

\section{Statistical analysis}

For all repeated data, incremental changes from baseline were first determined. Data then were analysed as repeated measures using the Mixed procedure of SAS (SAS Institute Inc., Cary, NC, USA). The main effects of protein pre-meal and time were tested and the interaction evaluated if significant. Dog and period were included as random effects in the model. All baseline ( $0 \mathrm{~h}$ samples) data were analysed using the Mixed procedure of SAS with the main effect of protein pre-meal tested. Dog and period again were included in the model as random effects. A $P$ value of 0.05 was considered significant and $P<0 \cdot 10$ was considered a trend.

\section{Results}

\section{Food intake}

Food intake (Table 1$)$ did not differ $(P=0.56)$ among premeals, when dogs were fed $100 \mathrm{~g}$ protein from each substrate, but incremental change in food intake decreased $(P<0 \cdot 01)$ over time, as would be expected.

\section{Plasma glucose and serum insulin}

Baseline plasma glucose concentrations did not differ among diets $(P=0.73)$ and averaged $5.8(\operatorname{sem} 0 \cdot 14) \mathrm{mmol} / \mathrm{l}$. Overall incremental change in blood glucose (Fig. 1(a)) was greater $(P=0.03)$ when dogs consumed pork and beef compared with chicken, and was lower when dogs consumed pollock compared with pork. Blood glucose generally decreased $(P<0.01)$ over time. At $5 \mathrm{~min}$ postprandially, glucose was lowest $(P=0.03)$ in dogs fed the chicken pre-meal compared with pork, beef and pollock. Baseline serum insulin concentrations did not differ among diets $(P=0.87)$ and averaged $107 \cdot 2$ (SEM 15.7) $\mathrm{mmol} / \mathrm{l}$. Incremental changes in insulin (Fig. 1(b)) were lower $(P=0.05)$ when dogs consumed pollock, pork and beef pre-meals compared with salmon. Insulin increased over time $(P<0.01)$ and had two peaks ( 5 and $30 \mathrm{~min}$ postprandially). At $30 \mathrm{~min}$ postprandially, insulin was greater $(P=0.02)$ with the salmon pre-meal compared with pollock, beef or pork. There were no differences in incremental area under the curve (AUC) for glucose or insulin.

\section{Serum total ghrelin and plasma glucagon-like peptide-1}

Baseline serum total ghrelin concentrations did not differ among diets $(P=0.62)$ and averaged 1.9 (SEM 0.35$) \mathrm{ng} / \mathrm{ml}$. Ghrelin incremental change (Fig. 2(a)) did not differ due to diet $(P=0.86)$, but decreased $(P<0.01)$ over time. Ghrelin was lower $(P=0.03)$ by $60 \mathrm{~min}$ postprandially, regardless of the protein pre-meal. Baseline plasma GLP-1 concentrations did not differ among diets $(P=0.66)$ and averaged $6 \cdot 1$ (SEM 2.72) pM. Incremental changes in GLP-1 (Fig. 2(b)) were lower $(P=0.04)$ when dogs consumed the pork, salmon and chicken pre-meals compared with beef. Overall, GLP-1 increased over time $(P<0 \cdot 01)$. There were no differences in incremental AUC for ghrelin or GLP-1.

\section{Plasma amino acids}

Incremental changes from baseline of plasma AA are presented in Fig. 3(a)-(e), Fig. 4(a)-(e) and Supplemental Fig. 1 (available online at http://www.journals.cambridge.org/bjn). Insulin-stimulating AA leucine $(P=0 \cdot 003)$, isoleucine $(P<0 \cdot 01)$ and histidine $(P<0 \cdot 01)$ incremental changes from baseline were greatest when dogs consumed the chicken pre-meal compared with pork, beef or pollock. The plasma glutamine incremental change from baseline decreased $(P<0 \cdot 01)$ when dogs consumed pork compared with all other pre-meals. There was an interaction between pre-meal and time $(P<0.01)$ in plasma histidine incremental change, with the chicken pre-meal increasing more $(P=0.001)$ after 60,90 and 120 min compared with all other pre-meals.

Valine $(P<0.01)$ and LNAA $(P=0.005)$ concentrations were greatest when dogs consumed the chicken pre-meal compared with pork, beef or pollock. Beef and pork pre-meals led to a lower $(P<0.01)$ overall plasma methionine change from baseline. Plasma taurine had a time $\times$ pre-meal interaction $(P<0 \cdot 01)$ where, at 60 min postprandially, the salmon pre-meal led to the greatest $(P<0 \cdot 01)$ taurine concentration compared with all other pre-meals, and the response

Table 1. Food intake values at $30,60,180$ and 1440 min after dogs were fed mammalian, avian or fish protein sources containing $100 \mathrm{~g}$ protein

(Mean values for nine or ten dogs)

\begin{tabular}{|c|c|c|c|c|c|c|c|c|c|}
\hline & \multicolumn{5}{|c|}{ Pre-meal } & \multirow[b]{2}{*}{ SEM } & \multicolumn{3}{|c|}{$P$} \\
\hline & Beef & Chicken & Pork & Pollock & Salmon & & Pre-meal & Time & Pre-meal $\times$ time \\
\hline Food intake (g) & & & & & & 87.25 & 0.56 & 0.0001 & 0.98 \\
\hline $30 \mathrm{~min}$ & $272 \cdot 2$ & 293.7 & 233.6 & $292 \cdot 1$ & 297.5 & & & & \\
\hline $60 \mathrm{~min}$ & $272 \cdot 2$ & 293.7 & 288.3 & $324 \cdot 0$ & 337.7 & & & & \\
\hline $180 \mathrm{~min}$ & 315.5 & $345 \cdot 0$ & 300.9 & 371.9 & $359 \cdot 2$ & & & & \\
\hline $1440 \mathrm{~min}$ & 509.4 & $495 \cdot 0$ & $527 \cdot 7$ & $509 \cdot 1$ & $490 \cdot 2$ & & & & \\
\hline
\end{tabular}



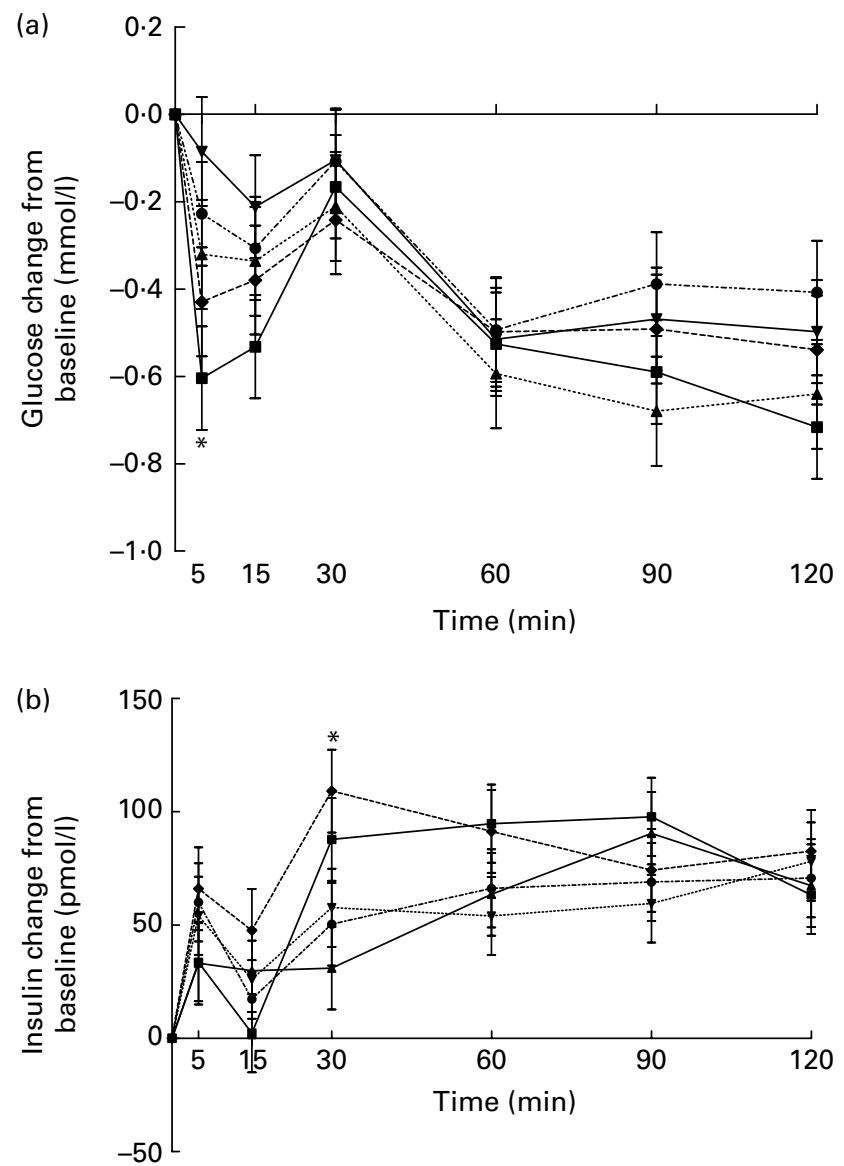

Fig. 1. (a) Incremental changes in glucose concentrations in dogs consuming mammalian ( $\bullet$, beef; $\mathbf{\Lambda}$, pork), avian ( $\mathbf{\square}$, chicken) or fish ( $\mathbf{\nabla}$, pollock; -, salmon) protein sources. Values are means, with pooled standard errors represented by vertical bars. There were treatment $(P=0.03)$ and time $(P<0.0001)$ effects but no treatment $\times$ time effect $(P=0.97) .{ }^{*}$ Mean value was significantly lower compared with those for pork, beef and pollock $(P<0.05)$. (b) Incremental changes in insulin concentrations in dogs consum-

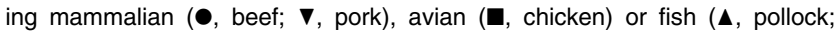
-, salmon) protein sources. Values are means, with pooled standard errors represented by vertical bars. There were treatment $(P=0.05)$ and time $(P<0.0001)$ effects but no treatment $\times$ time effect $(P=0.11)$. ${ }^{*}$ Mean value of chicken was significantly lower compared with those for pollock, beef and pork $(P<0.05)$.

following chicken was greater $(P<0 \cdot 01)$ than after the beef or pork pre-meals. The tryptophan:LNAA ratio tended $(P=0.08)$ to be greater when dogs consumed pork, salmon and pollock pre-meals compared with beef, and this ratio following pork tended $(P=0 \cdot 10)$ to be greater than after the chicken pre-meal.

Total AA $(P<0 \cdot 01)$ incremental changes from baseline were greatest when dogs consumed the chicken pre-meal compared with pork, beef or pollock. Most AA, except glutamine $(P=0.93)$, changed over time, with most increased $(P<0.01)$ from baseline by $60 \mathrm{~min}$. Leucine, asparagine, valine, histidine and LNAA concentrations increased $(P<0 \cdot 01)$ by $30 \mathrm{~min}$ postprandially, while others were increased $(P<0.01)$ by $60 \mathrm{~min}$ postprandially. Plasma methionine tended $(P=0 \cdot 09)$ to differ due to diet and time, with pollock increasing $(P<0 \cdot 01)$ from 60 to $90 \mathrm{~min}$ postprandially, while all other pre-meals plateaued after $60 \mathrm{~min}$.
Leucine $\quad(P=0.09), \quad$ isoleucine $\quad(P=0 \cdot 006), \quad$ histidine $(P=0.001)$ and valine $(P=0.02)$ incremental AUC (Table 2$)$ were greater when dogs consumed the chicken pre-meal. Methionine incremental AUC tended to be greater $(P=0.08)$ when dogs consumed chicken, pollock and salmon premeals. Taurine incremental AUC was greater $(P=0.003)$ when dogs consumed the salmon and pollock pre-meals. Incremental AUC was not affected by pre-meal for hydroxyproline, threonine, serine, asparagine, proline, glycine, alanine, citrulline, tryptophan, tyrosine, lysine, arginine, LNAA, tryptophan:LNAA or total (data not presented). All other changes in AA concentrations are provided in the online supporting material (available at http://www.journals.cambridge. org/bjn).

\section{Discussion}

The present study aimed to determine if differing protein sources affected satiety hormones, plasma AA associated

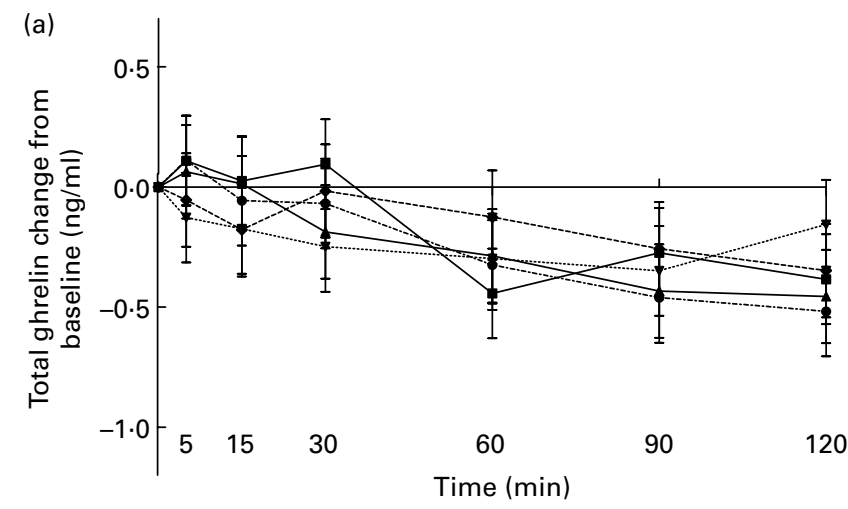

(b)

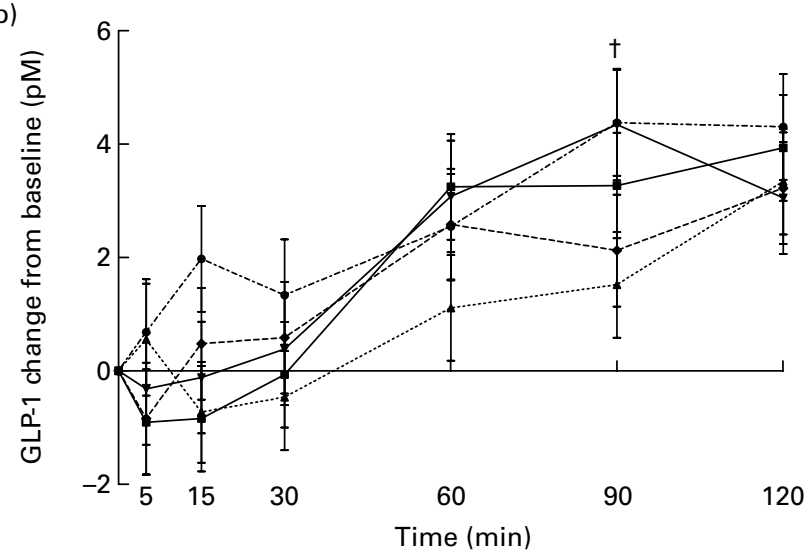

Fig. 2. (a) Incremental changes in total ghrelin concentrations in dogs after consuming mammalian ( $\bullet$, beef; $\boldsymbol{\nabla}$, pork), avian ( $\mathbf{\square}$, chicken) or fish $(\boldsymbol{\Lambda}$, pollock; $\bullet$, salmon) protein sources. Values are means, with pooled standard errors represented by vertical bars. There was a time effect $(P<0.0001)$, but no effects of treatment $(P=0.85)$ or treatment $\times$ time $(P=0.96)$. (b) Incremental changes in glucagon-like peptide-1 (GLP-1) concentrations in dogs after consuming mammalian ( $\bullet$, beef; $\boldsymbol{\Lambda}$, pork), avian $(\boldsymbol{\square}$, chicken) or fish ( $\mathbf{\nabla}$, pollock; $\bullet$, salmon) protein sources. Values are means, with pooled standard errors represented by vertical bars. There was a time effect $(P<0.0001)$, but no effects of treatment $(P=0.32)$ or treatment $\times$ time $(P=0.93)$. $†$ Mean value of beef and pollock tended to be significantly higher compared with those for pork or salmon $(P<0 \cdot 10)$. 

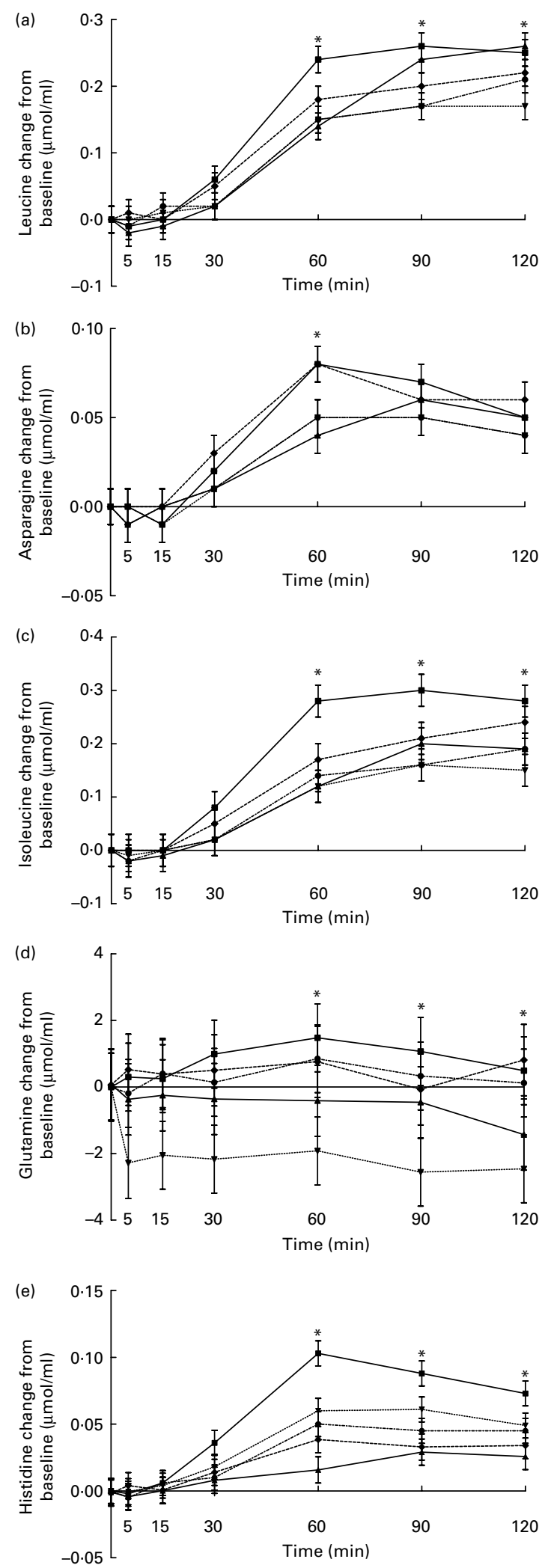

Fig. 3. Incremental changes in insulin-stimulating plasma amino acids leucine (a), asparagine (b), isoleucine (c), glutamine (d) and histidine (e) concentrations in dogs after consuming mammalian ( $\bullet$, beef; $\mathbf{\nabla}$, pork), avian $(\boldsymbol{\square}$, chicken) or fish ( $\boldsymbol{\Lambda}$, pollock; $\bullet$, salmon) protein sources. Values are means, with pooled standard errors represented by vertical bars. ${ }^{*} P<0.05$ (for contrasts, see Plasma amino acids section in the Results). with satiety and voluntary food intake. All dogs were provided pre-meals consisting of $100 \mathrm{~g}$ of each protein source; therefore, amount provided, fat concentration and other nutrient concentrations differed (Table 3). This was done to allow for accurate interpretation of changes in plasma AA concentrations. It was recognised that providing pre-meals as liquid slurries may have an impact on the retention time in the stomach, thereby influencing the satiety response. While the present study provides important data about the differences among satiety responses due to animal protein source, a voluntary food intake response was not demonstrated. The strength of these data is that all outside influences were controlled, which may indicate that there are limited differences in satiety among animal protein sources. Including a plantbased protein source may have aided data interpretation.

While we found no differences in voluntary food intake, fish proteins have been noted to be more satiating than beef ${ }^{(12,13)}$ and chicken ${ }^{(12)}$ in human studies. Uhe et al. ${ }^{(12)}$ noted that $50 \mathrm{~g}$ chicken or beef protein were equally less satiating compared with fish (Mustelus antarticus) protein using subjective hunger and fullness scores, but subsequent food intake was not different. Borzoei et al. ${ }^{(13)}$ noted no changes in subjective satiety scores between beef and fish protein-based lunches, and there was an $11 \%$ reduction in energy intake at the evening meal when fish protein was consumed. It is not completely unexpected that we were unable to reduce food intake in dogs after the consumption of a protein pre-meal. Again, many dogs, like humans, will over-consume when allowed ad libitum access to food. It should also be noted that these dogs are routinely limit-fed to maintain a healthy body weight and, therefore, the novelty of having copious amounts of food may have influenced results. Feeding to maintain body weight, however, was equally important, as circulating levels and the effectiveness of some satiety hormones can be affected by body fat mass. The weight of food provided is also known to correlate with satiety response ${ }^{(1)}$, which may have led to more variation in our data.

Glucose and insulin responses in the present study were similar to those in previous reports of glucose and insulin changes following a protein dose $\mathrm{d}^{(12,13)}$ or high-protein mixed meal $^{(18,19)}$ fed to human subjects. Soucy \& LeBlanc ${ }^{(20)}$ noted that in adult male subjects at $90 \mathrm{~min}$ after a $50 \mathrm{~g}$ protein pre-load from either beef or cod, insulin was greater compared with baseline and this difference was greater after the beef pre-meal. In the present study, we noted differences only at $30 \mathrm{~min}$ postprandially, with pollock (a white fish cod) having the lowest insulin value; however, this trend was not noted at $90 \mathrm{~min}$ as was noted by Soucy \& LeBlanc ${ }^{(20)}$. Unlike the results of the present study, Pal \& Ellis ${ }^{(21)}$ noted that insulin was greater at $30 \mathrm{~min}$ postprandially when adult male human subjects consumed tuna compared with turkey as fed in a chocolate-flavoured liquid pre-meal, and a greater drop occurred in glucose at $60 \mathrm{~min}$. The subjects also had lower voluntary food intake and a greater feeling of fullness after the tuna pre-meal $(50 \mathrm{~g})$ compared with turkey. This may indicate that individual meat sources should be evaluated to determine potential impacts on satiety, as all types of fish did not behave similarly. 

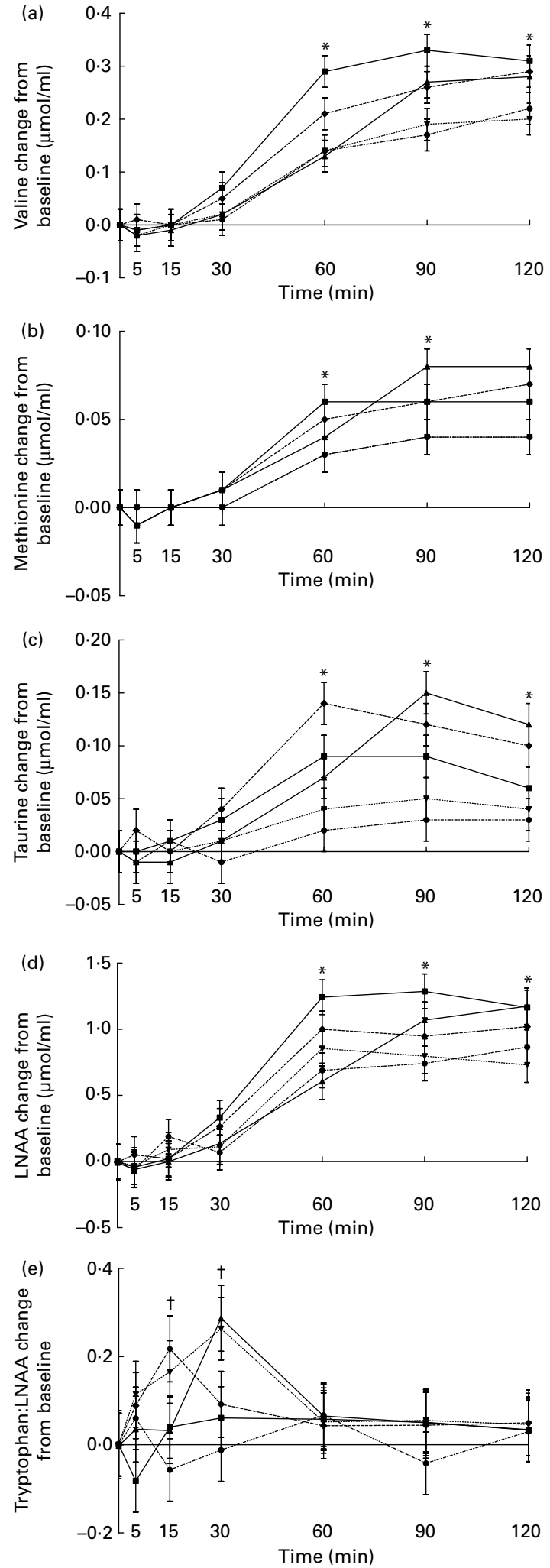

Fig. 4. Incremental changes in plasma amino acids valine (a), methionine (b) and taurine (c) concentrations, large neutral amino acids (LNAA) concentration (d) and tryptophan:LNAA ratio (e) in dogs after consuming mammalian $(\bullet$, beef; $\boldsymbol{\nabla}$, pork), avian ( $\boldsymbol{\square}$, chicken) or fish ( $\boldsymbol{\Lambda}$, pollock; $\bullet$, salmon) protein sources. Values are means, with pooled standard errors represented by vertical bars. * $P<0.05$, $† P<0.10$ (for contrasts, see Plasma amino acids section in the Results).
Total ghrelin responses in the present study were similar to those of Bowen et al. ${ }^{(22)}$ and Diepvens et al. ${ }^{(23)}$, where there was no effect of protein substrate on ghrelin concentrations throughout most of the postprandial test of adult human subjects. Diepvens et al. ${ }^{(23)}$ noted that milk protein and whey protein did not have the ghrelin-suppression capabilities of pea protein hydrolysate or whey protein + pea protein hydrolysate, but this was only noted at $120 \mathrm{~min}$ postprandially. To our knowledge, no published literature currently evaluates the effects of different animal protein sources on ghrelin. Total ghrelin remained suppressed after $120 \mathrm{~min}$ for all pre-meals, but it is unclear how physiologically relevant this small change was or how long this suppression lasts, as most dogs readily consumed two times their ME requirement within $3 \mathrm{~h}$ of the pre-meal. Ghrelin concentration decreases when subjects consume a high-protein meal compared with a highcarbohydrate meal ${ }^{(24)}$; however, some authors have argued that decreased ghrelin is unrelated to the satiating potential of high-protein meals ${ }^{(25-27)}$. While a high-protein $v$. lowerprotein meal may be able to suppress ghrelin, it does not appear to be affected by animal protein source.

Overall, the present results indicate that protein led to increases in GLP-1 after the consumption of a high-animal protein pre-meal, which is also noted in human subjects. The present results were similar to those of Diepvens et $a l{ }^{(23)}$; however, they noted that GLP-1 concentrations returned to baseline within $120 \mathrm{~min}$. In the present study, GLP-1 concentrations remained elevated after $120 \mathrm{~min}$. This prolonged effect may be due to the differences in protein dose between the two studies. Diepvens et al. ${ }^{(23)}$ provided human subjects $15 \mathrm{~g}$ of protein, while in the present study in dogs, $100 \mathrm{~g}$ of protein were consumed. More pronounced changes were noted by Bowen et al. ${ }^{(22)}$ when human subjects were fed $50 \mathrm{~g}$ of protein from soya, whey, gluten or glucose. This difference may be attributable to the fact that the liquid pre-load fed to subjects by Bowen et al. ${ }^{(22)}$ contained carbohydrates. It is noted that GLP-1 is increased after a highprotein meal ${ }^{(11,26)}$, and it is suggested that carbohydrates need to be included with the high-protein meal to stimulate the release of GLP-1 ${ }^{(28)}$. Because we had no carbohydrates

Table 2. Incremental area under the curve values for plasma amino acids in dogs fed mammalian, avian or fish protein sources

(Mean values with pooled standard errors for nine or ten dogs)

\begin{tabular}{lccccccc}
\hline & \multicolumn{7}{c}{ Pre-meal } \\
\cline { 2 - 8 } Item & Beef & Chicken & Pork & Pollock & Salmon & SEM & $P$ \\
\hline Tau & $2 \cdot 2^{\mathrm{a}}$ & $7 \cdot 5^{\mathrm{b}, \mathrm{c}}$ & $3 \cdot 7^{\mathrm{a}, \mathrm{b}}$ & $8 \cdot 9^{\mathrm{c}}$ & $10 \cdot 6^{\mathrm{c}}$ & $1 \cdot 72$ & 0.003 \\
Val & $13 \cdot 2^{\mathrm{a}}$ & $25 \cdot 3^{\mathrm{b}}$ & $13 \cdot 6^{\mathrm{a}}$ & $17 \cdot 5^{\mathrm{a}}$ & $20 \cdot 7^{\mathrm{a}, \mathrm{b}}$ & $3 \cdot 12$ & $0 \cdot 017$ \\
Met & $2 \cdot 9^{\mathrm{y}}$ & $4 \cdot 9^{\mathrm{z}}$ & $2 \cdot 9^{\mathrm{y}}$ & $5 \cdot 0^{\mathrm{z}}$ & $4 \cdot 9^{\mathrm{z}}$ & $0 \cdot 78$ & 0.08 \\
lle & $12 \cdot 6^{\mathrm{a}}$ & $23 \cdot 4^{\mathrm{b}}$ & $11 \cdot 4^{\mathrm{a}}$ & $13 \cdot 2^{\mathrm{a}}$ & $16 \cdot 6^{\mathrm{a}}$ & $2 \cdot 86$ & $0 \cdot 006$ \\
Leu & $13 \cdot 4^{\mathrm{y}}$ & $20 \cdot 5^{\mathrm{z}}$ & $12 \cdot 9^{\mathrm{y}}$ & $16 \cdot 0^{\mathrm{y}, \mathrm{z}}$ & $16 \cdot 3^{\mathrm{y}, \mathrm{z}}$ & $2 \cdot 40$ & 0.09 \\
His & $3 \cdot 9^{\mathrm{a}, \mathrm{b}}$ & $8 \cdot 0^{\mathrm{c}}$ & $4 \cdot 9^{\mathrm{b}}$ & $2 \cdot 3^{\mathrm{a}}$ & $3 \cdot 4^{\mathrm{a}, \mathrm{b}}$ & 0.99 & 0.001
\end{tabular}

a,b,c Mean values within a row with unlike superscript letters were significantly different $(P<0.05)$

$y, z$ Mean values within a row with unlike superscript letters tended to be significantly different $(P<0 \cdot 10)$. 
Table 3. Substrate, fat, fibre, gross energy and amino acid (AA) intake by dogs consuming mammalian, avian or fish protein sources (per $100 \mathrm{~g}$ protein)

\begin{tabular}{|c|c|c|c|c|c|}
\hline & \multicolumn{5}{|c|}{ Pre-meal } \\
\hline & Beef & Chicken & Pork & Pollock & Salmon \\
\hline Substrate $(\mathrm{g})$ & $120 \cdot 9$ & $110 \cdot 7$ & $116 \cdot 0$ & $103 \cdot 2$ & $107 \cdot 8$ \\
\hline Fat $(g)$ & $19 \cdot 8$ & $12 \cdot 3$ & $17 \cdot 9$ & 4.6 & $8 \cdot 2$ \\
\hline $\begin{array}{l}\text { Total dietary } \\
\text { fibre }(\mathrm{g})\end{array}$ & 1.5 & $1 \cdot 3$ & 0.3 & 0.3 & 0.2 \\
\hline \multicolumn{6}{|l|}{ Gross energy } \\
\hline $\mathrm{kJ}$ & 3035 & 2687 & 2864 & 2289 & 2525 \\
\hline kcal & 725.5 & $642 \cdot 3$ & 684.5 & $547 \cdot 0$ & 603.4 \\
\hline Protein (g) & $100 \cdot 0$ & $100 \cdot 0$ & $100 \cdot 0$ & $100 \cdot 0$ & $100 \cdot 0$ \\
\hline \multicolumn{6}{|l|}{$A A(g)$} \\
\hline His & $3 \cdot 6$ & $3 \cdot 5$ & $3 \cdot 6$ & $2 \cdot 0$ & $2 \cdot 3$ \\
\hline Ile & 4.6 & 4.5 & $4 \cdot 3$ & 4.4 & 4.4 \\
\hline Leu & 7.9 & 7.5 & $7 \cdot 3$ & $7 \cdot 8$ & $7 \cdot 3$ \\
\hline Lys & $8 \cdot 3$ & $8 \cdot 3$ & $8 \cdot 0$ & 8.9 & 8.4 \\
\hline Met & 2.5 & $2 \cdot 6$ & $2 \cdot 4$ & $3 \cdot 0$ & $2 \cdot 8$ \\
\hline Phe & 3.9 & 3.7 & 3.6 & 3.7 & $3 \cdot 7$ \\
\hline Thr & $4 \cdot 2$ & 4.0 & 4.0 & $4 \cdot 1$ & 4.1 \\
\hline Trp & $1 \cdot 1$ & $1 \cdot 2$ & $1 \cdot 1$ & 1.0 & $1 \cdot 1$ \\
\hline Val & 4.9 & $4 \cdot 8$ & $4 \cdot 6$ & 4.9 & $5 \cdot 0$ \\
\hline Ala & $5 \cdot 6$ & $5 \cdot 4$ & $5 \cdot 2$ & $5 \cdot 7$ & 5.5 \\
\hline Arg & $6 \cdot 1$ & $6 \cdot 0$ & $5 \cdot 8$ & $6 \cdot 1$ & 5.5 \\
\hline Asn & $8 \cdot 7$ & $8 \cdot 6$ & $8 \cdot 3$ & $9 \cdot 6$ & 9.0 \\
\hline Cys & $1 \cdot 0$ & 0.9 & 0.7 & 0.9 & 0.9 \\
\hline Gln & $13 \cdot 7$ & $12 \cdot 7$ & $12 \cdot 7$ & $13 \cdot 8$ & $12 \cdot 4$ \\
\hline Gly & 4.5 & $4 \cdot 2$ & $4 \cdot 3$ & $4 \cdot 6$ & $4 \cdot 3$ \\
\hline Нур & 0.5 & 0.3 & 0.5 & $0 \cdot 2$ & 0.2 \\
\hline Pro & 3.5 & $3 \cdot 1$ & 3.4 & $3 \cdot 1$ & 3.0 \\
\hline Ser & $3 \cdot 3$ & $3 \cdot 3$ & $3 \cdot 2$ & $3 \cdot 7$ & $3 \cdot 3$ \\
\hline Tau & $0 \cdot 1$ & $0 \cdot 1$ & 0.2 & $0 \cdot 6$ & 0.5 \\
\hline Tyr & 3.3 & $2 \cdot 8$ & $3 \cdot 2$ & 3.3 & $3 \cdot 2$ \\
\hline Total AA & $91 \cdot 8$ & $87 \cdot 8$ & 86.9 & $91 \cdot 7$ & $87 \cdot 3$ \\
\hline
\end{tabular}

in our pre-meal, GLP-1 may not have changed as drastically as it would have done if a complete meal had been consumed.

Changes in plasma AA concentrations are affected by the AA content of the meal ingested, rate of digestion and absorption, and metabolism by the enterocyte and liver ${ }^{(29)}$. Several AA have been suggested to be insulinogenic and/or satiating. The five AA with the most insulin-stimulating activity in dogs include tryptophan, leucine, asparagine, isoleucine and glutamine ${ }^{(30)}$. Leucine, asparagine, isoleucine and glutamine were all affected by the pre-meal and were greatest when dogs consumed the chicken and salmon pre-meals, which correspond with the insulin responses to these pre-meals. Tryptophan was not affected by diet in the present study. In human subjects, arginine is a noted insulinogenic $\mathrm{AA}^{(31)}$; however, only essential AA were tested by Rocha et $a l^{(30)}$, and all were noted to have some degree of insulinogenic activity, with histidine having the lowest capacity. Plasma arginine was not affected by the protein substrate in the present study.

Soucy \& LeBlanc ${ }^{(20)}$ noted differences between beef and fish plasma AA concentrations $90 \mathrm{~min}$ postprandially for arginine, histidine and lysine in adult males. Of these AA, only histidine was affected in the present study. Soucy and LeBlanc ${ }^{(20)}$ noted increased histidine concentrations following beef compared with a fish pre-meal. This is similar to results of the present study, as the two fish sources led to lower overall histidine incremental changes. This is probably due to the lower histidine concentrations in the fish pre-meals compared with the mammalian and avian sources in which similar compositional differences were noted by Soucy \& LeBlanc ${ }^{(20)}$. Although histidine was not identified as a major insulinogenic AA in dogs, other researchers have noted that carnosine (composed of histidine and $\beta$-alanine) or histidine increased plasma insulin ${ }^{(32)}$. Histidine, however, is not known to play a role in satiety.

Hall et al. ${ }^{(29)}$ noted increases in total plasma AA of human subjects fed a liquid pre-load of $48 \mathrm{~g}$ casein or whey protein. Whey protein led to a larger increase in total plasma AA, with the most dramatic difference between the two protein sources occurring $80 \mathrm{~min}$ postprandially. Whey also was noted to lead to greater concentrations of anorexigenic hormones, as well as a greater feeling of satiety by respondents. The authors noted that phenylalanine and tryptophan, AA associated with increased satiety ${ }^{(33)}$, were not affected in their study. This was similar to the present results showing that protein substrate did not affect phenylalanine or tryptophan, but both increased over time by $60 \mathrm{~min}$ postprandially.

Uhe et $a l .{ }^{(12)}$ noted changes in plasma AA profiles after the consumption of $50 \mathrm{~g}$ protein from beef (topside steak), chicken (breast) or fish (Mustelus antarcticus) by adult male subjects. The authors noted increases in plasma taurine (45, 60, $90 \mathrm{~min}$ postprandially) and methionine (90, 150, 180 min postprandially) when subjects consumed the fish pre-meal. The change in tryptophan:LNAA ratio also was greater ( 45 and $60 \mathrm{~min}$ postprandially) after consumption of the fish pre-meal ${ }^{(12)}$. The authors attributed the increase in satiety scores noted in their study (fish being more satiating) to the tryptophan:LNAA ratio, suggesting an increase in serotonin activity. Normally, after ingestion of proteins, the tryptophan (a precursor for serotonin):LNAA ratio decreases, thereby limiting the amount of serotonin able to pass the blood-brain barrier. Therefore, increasing this ratio may lead to increased satiety by allowing more tryptophan to pass through this barrier. In the present study, a trend was noted for a greater tryptophan:LNAA ratio when dogs consumed pork, pollock or salmon meal, but was highest with a pork pre-meal. As noted previously, there were no changes in subsequent food intake after the pre-load meal; it is unclear if this greater ratio influenced feelings of satiety in the dog.

Satiety has been reported to be affected in high- $v$. normalsoyaprotein diets due to insulin and plasma taurine concentrations in human subjects ${ }^{(34)}$. The authors noted a positive relationship of taurine concentration with satiety visual analogue scale (VAS) AUC ( $r 0.39 ; P<0.05)$; taurine concentration was also was negatively correlated with hunger VAS AUC $(r-0.43 ; P<0.05)^{(34)}$. In the present study, we found no correlation between the weight of food consumed $(\mathrm{g})$ at 30 , 60 or $180 \mathrm{~min}$ and positive taurine AUC (data not reported). The weight of food consumed $(\mathrm{g})$ by $1440 \mathrm{~min}$ after feeding tended to be correlated $(r-0 \cdot 25 ; P=0 \cdot 08)$ with positive taurine AUC, meaning the higher the taurine AUC, the less food a dog consumed. These results are in agreement with VAS correlations presented by Veldhorst et al. ${ }^{(34)}$. 


\section{Conclusions}

While we were able to influence satiety hormones and plasma $\mathrm{AA}$ in the dog after a protein pre-meal, we were unable to influence food intake. Numerically, dogs consumed the least amount of food after the consumption of a salmon or chicken pre-meal. This corresponds with many responses noted with decreased glucose and ghrelin and increased insulin, GLP-1, most insulin-stimulating AA and LNAA. The present study, along with other studies reporting variable results, may indicate that each protein source should be evaluated individually. Earlier reports of fish proteins being more satiating were conducted with Ling fish, a white fish. In the present study, we found that pollock, also a white fish, led to few changes in satiety-related hormones. Again, these substrates were provided in liquid slurries, which may make an impact on retention time in the stomach as well as other indices of satiety. The present study also was conducted using an acute one-time dose of each substrate. Feeding these protein sources as the main dietary protein source in mixed diets may lead to different results. These data, however, provide a starting point for evaluating whole-meal protein sources, with chicken and salmon leading to the greatest changes in satiety response.

Given that the test substrates were human-grade proteins, similar results would be expected in human subjects as well. Using these substrates with human subjects would allow for subjective determinations of satiety, which cannot be measured in dogs. Furthermore, pure skeletal muscle, the high-quality substrates used in the present study, are not commonly utilised in dog diets due to expense. Evaluation of by-products commonly used in the petfood industry may lead to different results, as common fish by-products vary in AA content compared with the substrates used in the present study ${ }^{(14,35)}$. Finally, fish proteins appeared to have similar abilities in modifying satiety markers as compared with avian or mammalian protein sources, but none was able to reduce voluntary food intake in the present study.

\section{Acknowledgements}

The present study was supported in part by a US Department of Agriculture, Agricultural Research Service (USDA/ARS) Cooperative agreement.

B. M. V. B. and K. S. S. designed the research; B. M. V. B., T. A. F. and L. L. B. conducted the research; B. M. V. B. analysed the data; S. S., P. J. B. and T. A. F. provided essential materials for this research; B. M. V. B. wrote the manuscript; and G. C. F. had primary responsibility for the final content. All authors read and approved the final manuscript.

P. J. B. works for the USDA/ARS who provided partial funding for the present study. B. M. V. B., T. A. F., L. L. B., K. S. S., S. S. and G. C. F. have no conflicts of interest.

\section{References}

1. Holt SHA, Brand Miller JC, Petocz P, et al. (1995) A satiety index of common foods. Eur J Clin Nutr 49, 675-690.
2. Cummings DE \& Overduin J (2007) Gastrointestinal regulation of food intake. J Clin Invest 117, 13-23.

3. Delzenne N, Blundell J, Brouns F, et al. (2010) Gastrointestinal targets of appetite regulation in humans. Obes Rev 11, $234-250$.

4. Tannous dit El Khoury D, Obeid O, Azar ST, et al. (2006) Variations in postprandial ghrelin status following ingestion of high-carbohydrate, high-fat, and high-protein meals in males. Ann Nutr Metab 50, 260-269.

5. Wettergren A, Schjoldager B, Mortensen PE, et al. (1993) Truncated GLP-1 (proglucagon 72-107-amide) inhibits gastric and pancreatic functions in man. Dig Dis Sci 38, 665-673.

6. Turton MD, O'Shea D, Gunn I, et al. (1996) A role for glucagon-like peptide-1 in the central regulation of feeding. Nature 379, 69-72.

7. Tang-Christensen M, Larsen PJ, Göke R, et al. (1996) Central administration of GLP-1 (7-36) amide inhibits food and water intake in rats. Am J Physiol 271, R848-R856.

8. Strader AD \& Woods SC (2005) Gastrointestinal hormones and food intake. Gastroenterology 128, 175-191.

9. Mellinkoff S (1957) Digestive system. Annu Rev Nutr 19, 175-204.

10. Barkeling B, Rossner S \& Bjorvell H (1990) Effects of a highprotein meal (meat) and a high-carbohydrate meal (vegetarian) on satiety measured by automated computerized monitoring of subsequent food intake, motivation to eat and food preferences. Int J Obes 14, 743-751.

11. Johnson J \& Vickers Z (1993) Effects of flavor and macronutrient composition of food servings on liking, hunger and subsequent intake. Appetite 21, 25-39.

12. Uhe AM, Collier GR \& O'Dea K (1992) A comparison of the effects of beef, chicken and fish protein on satiety and amino acid profiles in lean male subjects. J Nutr 122, 467-472.

13. Borzoei S, Neovius M, Barkeling B, et al. (2006) A comparison of effects of fish and beef protein on satiety in normal weight men. Eur J Clin Nutr 60, 897-902.

14. Faber TA, Bechtel PJ, Hernot DC, et al. (2010) Protein digestibility evaluations of meat and fish substrates using laboratory, avian, and ileally cannulated dog assays. J Anim Sci 88, 1421-1432.

15. Knapp BK, Parsons CM, Swanson KS, et al. (2008) Physiological responses to novel carbohydrates as assessed using canine or avian models. J Agric Food Chem 56, 7999-8006.

16. Vester BM, Liu KJ, Keel TL, et al. (2009) In utero and postnatal exposure to a high-protein or high-carbohydrate diet leads to differences in adipose tissue mRNA expression and blood metabolites in kittens. Br J Nutr 102, 1136-1144.

17. Lubbs DC, Vester Boler BM, Ridge TK, et al. (2010) Dietary macronutrients and feeding frequency affect fasting and postprandial concentrations of hormones involved in appetite regulation in adult dogs. J Anim Sci 88, 3945-3953.

18. Schmid R, Schusdziarra V, Schulte-Frohlinde E, et al. (1989) Role of amino acids in stimulation of postprandial insulin, glucagon, and pancreatic polypeptide in humans. Pancreas 4, 305-314.

19. Lang V, Bellisle F, Oppert JM, et al. (1998) Satiating effect of proteins in healthy subjects: a comparison of egg albumin, casein, gelatin, soy protein, pea protein, and wheat gluten. Am J Clin Nutr 67, 1197-1204.

20. Soucy J \& LeBlanc J (1999) The effects of a beef and fish meal on plasma amino acids, insulin and glucagon levels. Nutr Res 19, 17-24.

21. Pal S \& Ellis V (2010) The acute effects of four protein meals on insulin, glucose, appetite, and energy intake in lean men. Br J Nutr 104, 1241-1248. 
22. Bowen J, Noakes M \& Clifton PM (2006) Appetite regulatory hormone responses to various dietary proteins differ by body mass index status despite similar reductions in ad libitum energy intake. J Clin Endocrinol Metab 91, 2913-2919.

23. Diepvens K, Häberer D \& Westerterp-Plantenga M (2008) Different protein and biopeptides differently affect satiety and anorexigenic/orexigenic hormones in healthy humans. Int J Obes 32, 510-518.

24. Blom WAM, Lluch A, Stafleu A, et al. (2006) Effect of a highprotein breakfast on the postprandial ghrelin response. $A m J$ Clin Nutr 83, 211-220.

25. Moran LJ, Luscombe-Marsh ND, Noakes M, et al. (2005) The satiating effect of dietary protein is unrelated to postprandial ghrelin secretion. J Clin Endocrinol Metab 90, 5205-5211.

26. Lejeune MP, Westerterp KR, Adam TC, et al. (2006) Ghrelin and glucagon-like peptide 1 concentrations, 24-h satiety, and energy and substrate metabolism during a high-protein diet and measured in a respiration chamber. Am J Clin Nutr 83, 89-94.

27. Smeets AJ, Soenen S, Luscombe-Marsh ND, et al. (2008) Energy expenditure, satiety, and plasma ghrelin, glucagonlike peptide 1 , and peptide tyrosine-tyrosine concentrations following a single high-protein lunch. J Nutr 138, 698-702.

28. Veldhorst M, Smeets A, Soenen S, et al. (2008) Protein induced satiety: effects and mechanisms of different proteins. Physiol Behav 94, 300-307.
29. Hall WL, Millward DJ, Long SJ, et al. (2003) Casein and whey exert different effects on plasma amino acid profiles, gastrointestinal hormone secretion and appetite. Br J Nutr 89, 239-248.

30. Rocha DM, Faloona GR \& Unger RH (1972) Glucagon-stimulating activity of 20 amino acids in dogs. J Clin Invest 51, $2346-2351$.

31. Floyd JC Jr, Fajans SS, Conn JW, et al. (1966) Stimulation of insulin secretion by amino acids. J Clin Invest 45, $1487-1502$.

32. Leblanc J \& Soucy J (1994) Hormonal dose-response to an adenosine receptor agonist. Can J Physiol Pharmacol 72, 113-116.

33. Muurahainen N, Kissileff HR, Derogatis AJ, et al. (1988) Effects of cholecystokinin-octapeptide (CCK-8) on food intake and gastric emptying in man. Physiol Behav 44, 645-649.

34. Veldhorst MAB, Nieuwenhuizen AG, Hochstenbach-Waelen A, et al. (2009) Effects of high and normal soyprotein breakfasts on satiety and subsequent energy intake, including amino acid and 'satiety' hormone responses. Eur J Nutr $\mathbf{4 8}$, 92-100.

35. Folador JF, Karr-Lilienthal LK, Parsons CM, et al. (2006) Fish meals, fish components, and fish protein hydrolysates as potential ingredients in pet foods. J Anim Sci 84, 2752-2765. 